\title{
Sedentary behavior, unhealthy food consumption and dental caries in 12-year-old schoolchildren: a population-based study
}

Rafael Aiello BOMFIM(a)

Antonio Carlos FRIAS ${ }^{(b)}$

Andreia Morales CASCAES(c)

Luiz Eugênio Nigro MAZZILLI(b) iD

Luciana Bronzi de SOUZA(d)

Fernanda Campos de Almeida CARRER $^{(b)}$ iD

Maria Ercília de ARAÚJO(b) i

(a) Universidade Federal do Mato Grosso do Sul - UFMS, School of Dentistry, Department of Community Health, Campo Grande, MS, Brazil.

(b) Universidade de São Paulo - USP, School of Dentistry, Department of Community Health, São Paulo, SP, Brazil.

(c) Universidade Federal de Santa Catarina - UFSC, Department of Public Health, Florianópolis, SC, Brazil

(d) Universidade Federal de Goiás - UFG, School of Nutrition, Department of Community Health, Goiânia, GO, Brazil

Declaration of Interests: The authors certify that they have no commercial or associative interest that represents a conflict of interest in connection with the manuscript.

Corresponding Author:

Rafael Aiello Bomfim

E-mail: aiello.rafael@gmail.com

htrps://doi.org/10.1590/1807-3107bor-2021.vol35.0041

Submitted: February 20, 2020

Accepted for publication: October 20, 2020

Last revision: December 14, 2020
Abstract: This study analyzed the association between sedentary behavior (SB), unhealthy food consumption, and dental caries amongst 12-year-old schoolchildren. An epidemiological survey was carried out in the five largest cities (> 80,000 inhabitants) of the State of Mato Grosso do Sul, Brazil. Data were collected on decayed, missing and filled teeth index (DMFT), sociodemographic characteristics, SB, unhealthy food consumption, and water fluoridation status. The analysis was based on the theoretical framework established by J Sisson. Structural equation models were performed to test the association of dental caries experience with sociodemographic, contextual, and behavioral factors. The mean DMFT index in the five cities was 1.02 (95\%CI: 0.39-1.66). Higher sedentary behavior (more than 2 hours/day) [standardized coefficient (SC) $=0.21$ 95\%CI: 0.07-0.39] and higher unhealthy food consumption (more than 4 times/week) $[\mathrm{SC}=0.23(0.10-0.45)]$ were associated with higher DMFT index than their counterparts. Also, cities with fluoridated water were associated with lower DMFT index [SC $=-0.85(-1.20--0.50)]$. Families who had a per capita income above the poverty line had a direct association with unhealthy food consumption [SC $=-0.24(-0.38--0.11)]$. Unhealthy food consumption mediated the association of sedentary behavior on DMFT index [SC=0.07 (0.02-0.13)]. Sensitivity analysis confirmed the findings. Sedentary behavior mediated by unhealthy food consumption had a significant association with dental caries experience. Public policies must address transdisciplinary actions to reduce sedentary behavior and unhealthy food consumption and promote water fluoridation.

Keywords: Dental Caries; Sedentary Behavior; Epidemiology; Diet, Food, and Nutrition.

\section{Introduction}

The widespread use of social media and the internet brought benefits such as greater access to information, especially among children and adolescents. However, it can also be detrimental to health, especially among the new generations that are growing with the various technologies that are rapidly advancing. ${ }^{1,2}$ Sedentary behavior (SB) 
was conceptualized as any activity with an energy cost equal to or less than 1.5 metabolic equivalents (METs), ${ }^{3,4}$ usually performed with the person in a reclined or seated position.

Childhood and adolescence are particularly relevant times for the study of sedentary behavior because it is a critical period in which behavioral changes are concentrated. ${ }^{5}$ There is evidence that sedentary behavior has a direct impact on health outcomes such as obesity, metabolic syndrome, cardiovascular diseases, ${ }^{1}$ and in the practice of physical activity. ${ }^{6}$ The American Academy of Pediatrics defines a cutoff point for sedentary behavior as $\geq 2 \mathrm{hs}$ /day of television (TV) watching. ${ }^{7}$ One study evaluated sedentary behavior measured by TV time ( $\geq 2 \mathrm{hs} /$ day) with dental caries in Chinese adolescents, finding positive associations even after adjusting for demographic and behavioral factors. ${ }^{8}$ Recent systematic reviews have found an association of TV/screen time with unhealthy food consumption (high-sugar foods) in children'. Another review has found that having a TV on at mealtimes increased consumption of high-fat-high-sugar foods and sugar-sweetened beverages ${ }^{10}$ and reduced consumption of fruit and vegetables, which could lead to higher prevalence of dental caries and increased DMFT (decayed, missing and filled teeth index) values. In Brazil, the mean score of DMFT index in 12 year-old children has reduced from 2.8 in 2003 to 2.1 in 2010. However, these improvements have benefited more the groups with higher socioeconomic status. ${ }^{11,12}$ Most of the improvements have been attributed to better living conditions and stronger oral health policies, improving water fluoridation and fluorides in toothpaste. ${ }^{13}$

Sedentary behavior is a latent variable that cannot be measured but can be the result of the interaction of several observable variables like time spent watching TV, playing games, sitting, and on the internet. Models with complex interactions like food consumption and SB differ from traditional regression models that allow us to study only one outcome. Also, they are useful for studying direct and indirect mechanisms between observable (unhealthy food consumption) and latent variables, which may contribute to better define complex interactions in public health. Structural equation models (SEM) are the models used to measure these interactions. Unhealthy food consumption, dental caries experience, and sedentary behavior may have complex interactions in public health.

The objective of the present study was to verify the associations between sedentary behavior, unhealthy food consumption, and dental caries among schoolchildren participating in a population-based study conducted in Mato Grosso do Sul, Brazil. The hypothesis tested was that there is an association between sedentary behavior, via unhealthy food consumption, and impact on dental caries represented by DMFT index, using the Sisson theoretical framework $^{14}$ to conduct the analyses.

\section{Methodology}

This study was a population-based epidemiological survey representing the five largest cities (over than 80,000 inhabitants) in the State of Mato Grosso do Sul, Brazil, as follows: Campo Grande, Corumbá, Dourados, Ponta Porã, and Três Lagoas. In 2018, Campo Grande, the state capital, had 860,000 inhabitants, Dourados had 220,925 inhabitants and is the second largest city, Corumbá had 119,465, Três Lagoas, 119,464, and Ponta Porã, 92,526 inhabitants, and together have more than half of 2.748.023 inhabitants of the 79 cities in the State ${ }^{15}$. These five cities are the most representative of the four territorial macro-regions in the State (Dourados and Ponta porã are in the same macro-region) and are the most affluent areas. The sampling plan was prepared by a conglomerate in two stages of probabilities proportional to size (PPS). The five cities were the Primary Sampling Units (PSU) and the public municipal elementary schools were the Secondary Sampling Units (SSU). Our prominent national epidemiological survey (SBBrasil 2010) had selected 32 SSU per city, and we followed those guidelines ${ }^{16}$. Therefore, we considered interviewing and collecting data from 32 schools in the two major cities (which have more than 32 schools), and if the number of schools was lower than 32, we considered interviewing all schools in the city. In 2018, the total number of public elementary schools in Campo Grande was 86, in Dourados, 45, in Corumbá, 26, in Três Lagoas,17, and in Ponta Porã, 8. 


\section{School selection}

A random drawing of 32 schools in Campo Grande and Dourados was done. All schools of Corumbá ( $\mathrm{n}=26)$, Três Lagoas $(\mathrm{n}=17)$, and Ponta Porã $(\mathrm{n}=8)$ were previously selected, totalizing 115 schools that composed the survey.

\section{Students' selection}

The students were selected by drawing through a coordination list from the director/manager board in the age group of interest (12 year-olds). Ten students were selected if there was only one classroom in the school, and if there was more than one classroom, the equal proportionality per classroom was respected.

\section{Sample size}

A formula ${ }^{17}$ was used to calculate the sample size for dental caries, which considers the values of the mean and standard deviation of the DMFT index in Central-west region of Brazil, according to the SBBrasil 2010.16

Formula 1 - Calculation of the sample

$$
n=\frac{\left(\frac{\left(Z^{2} \times S^{2}\right)}{(X \times \varepsilon)^{2}} x \text { Deff }\right)}{(1-N R R)}
$$

where $\mathrm{n}$ = final sample size; $\mathrm{Z}=$ significance level of 1.96 , which corresponds to a $95 \%$ confidence, i.e. $\alpha=0.05 ; S^{2}=$ variance of the sample mean, i.e., the square of the standard deviation of the variable (1.81); $\mathrm{X}=$ mean DMFT in Central-West region, according to SBBrasil 2010 (mean=2.63); $\varepsilon=$ acceptable error margin or tolerated error $(\varepsilon=0.10)$; deff $=$ "design effect" (deff = 2.0); NRR = non-response rate $(30 \%$ estimated denials to participate).

The calculated sample size was 520 schoolchildren, including denials (30\%). Considering the 115 eligible schools, we had around five students per school. After accounting for $35 \%$ of school denials due to school principals unwilling to participate, seven students per school were estimated, which we opted to round up to 10 students per school.

\section{Oral health teams' calibration}

Five dental teams in each city, composed by a dentist and an annotator, received explanations with 32 hours of practical training, based on consensus.
The intra- and inter-examiner reliability test showed a Kappa coefficient of 0.73 .

\section{Data collection}

Data were collected through questionnaires. The sociodemographic questionnaires were sent by the principal to parents/guardians. After that, the adolescent returned the questionnaire to the principal, who communicated the dentist team responsible for data collection. Thus, the epidemiological examination was carried out at the school. The students answered questionnaires on food consumption, sedentary behavior, and oral hygiene before the clinical exam.

\section{Theoretical framework model}

The theoretical model of Sisson ${ }^{14}$, developed to explain social inequalities in oral health, was adopted. We used variables that provided material explanation and linked to the individual's position in the social structure, measured by the parent's education equalized by per capita income. Variable reflecting health-damaging choices, such as inadequate tooth brushing, sedentary behavior, and unhealthy food consumption, measured the cultural/behavioral explanations. These are modifiable factors and can be affected by socioeconomic status (SES). Access to public supply of fluoridated water measured the contextual perspective of the Sisson's model.

\section{Main outcome}

The outcome variable was the DMFT index, as recommended by the World Health Organization ${ }^{18}$. The index measures the caries experience of 12 year-old children. In the survey, caries was considered a groove, fissure or smooth surface of a tooth that presented an evident cavity or softened tissue at the base of the enamel, or discoloration of the enamel, or a temporary restoration (except glass ionomer). The CPI probe was used to confirm visual evidence of caries on the occlusal, buccal, and lingual surfaces.

\section{Sedentary behavior measure (main exposure)}

The instrument to measure sedentary behavior ${ }^{7}$ was translated from the instrument drafted by Rey-Lopez et al. ${ }^{19}$ and used to measure the outcome 
in the HELENA study. The questionnaire measures total SB based on weekdays and weekends in four main domains (TV, internet, video games, and sitting activities). Each response option has seven categories: 0 minutes; less than 30 minutes; 30 minutes to 1 hour; more than 1 hour to 2 hours; more than 2 hours to 3 hours; more than 3 hours to 4 hours; and more than 4 hours per day. In order to achieve the total daily hours spent on such activities, we considered the mean point in each category. The American Academy of Pediatrics defines a cutoff point of $\geq 2 \mathrm{hs}$ /day for sedentary behavior watching TV. As we have four main domains ( $\mathrm{TV}$, games, internet, and sitting), we considered the sum of all domains being $\geq 2 \mathrm{hs}$ /day to classify the schoolchildren as having sedentary behavior. We used the adapted formula ${ }^{7}$ to calculate the total SB.

$$
\text { Total } S B=\frac{(\text { weekdays } x 5)+(\text { weekends } \times 2)}{7}
$$

In our structural equation model, SB was represented by a latent variable. Each domain represents a continuous measure depending on the number of hours of self-reported SB from 0 (no sedentary behavior) to 7 (four or more hours per day) in each domain. We use Cronbach's alpha to measure the instrument reliability ${ }^{20}$, considering the total SB of the instrument (four main domains).

\section{Unhealthy food consumption}

The weekly frequency of unhealthy food consumption was investigated using an instrument recommended by the Brazilian Ministry of Health ${ }^{15}$, containing five food-items, answered by the adolescent. The instrument was used to evaluate the number of times/week each unhealthy food was consumed on a continuous scale from 0 to seven times/week. The unhealthy foods investigated were: a) French fries, potatoes chips, and fried snacks; b) hamburger and sausages (sausage, salami, sausage ham, etc.); c) salty crackers; d) sweet or sandwich cookies with filling / cookies, candies, and chocolates (in bars or candy); e) regular soft drinks consumption. Afterwards, we stratified the weekly consumption of unhealthy foods into: low $=$ up to 2 times a week (0), moderate $=2$ to 4 times $/$ week (1), and high $=$ more than 4 times a week (2). ${ }^{21}$ As we had five food items, we considered the sum of all unhealthy food items to classify the participant according to the three categories, using the adapted formula:

$\begin{gathered}\text { Unhealthy food } \\ \text { consumption }\end{gathered}=\frac{\text { Sum of the frequency of } 5 \text { food items }}{5}$

\section{Covariates}

Sex was dichotomized into male (0) and female (1). Equalized per capita income was dichotomized into up to poverty level (0) and above the poverty level (1) in Brazilian context ( $\mathrm{R} \$ 466 /$ month in 2018 / US\$120.4) based in the mid-point of open-ended income. ${ }^{22}$ The self-reported ethnic group was stratified into 0 (white) and 1 (black, brown, yellow, indigenous) ${ }^{15}$. The parent's educational level was stratified into primary school grades 1-4 (0) and above grade 4 (1). Brushing teeth was stratified into up to 1 time per day (0) and two or more times per day (1).

The fluoridation variable was extracted from the measurements made in the Vigiflúor survey of 2017, which offers the most current data on fluoridation of the public water supply in the State of Mato Grosso do Sul. ${ }^{23}$ Campo-Grande, Dourados, and Corumbá were classified as fluoridated cities (1) and Três Lagoas and Ponta Porã as non-fluoridated (0). The mean fluoride concentration in Campo Grande was $0.6 \mathrm{mg} / \mathrm{L}$, in Dourados was $0.45 \mathrm{mg} / \mathrm{L}$, in Corumbá was $0.5 \mathrm{mg} / \mathrm{L}$, in Três Lagoas was 0 and Ponta Porã was $0.1 \mathrm{mg} / \mathrm{L} .^{23}$

\section{Statistical analysis}

We performed a descriptive analysis, considering 95\% confidence intervals. The structural equation models were used to analyze the data and consisted of two sub-models: the measurement model, which establishes how the latent constructs are measured, and the structural model, which analyzes the structural relationship of, and the associations between the variables. ${ }^{2}$. In the present study, the latent variable (SB) was extracted from the HELENA questionnaire. ${ }^{7}$ All the other independent variables were included. SEM was used to estimate the direction of the association between the variables and dental caries (sum of decayed, filled and missing teeth). Standardized coefficients (SCs) were interpreted as SC $<0.10$ being a small association, SCs from 0.30 to 0.50 , a medium association, and a SCs $>0.50$, a strong association. ${ }^{24}$ 
The goodness of fit of the model was evaluated by ordinary comparison, and complemented by applying the mean square error of approximation (RMSEA), where values less than or equal to 0.08 are considered adequate. The Comparative Fit Index (CFI) and the Tucker-Lewis Index (TLI) provided additional reliability, and values above 0.80 were considered adequate ${ }^{25}$. All analyses were performed using STATA v.14 software (College Station,, USA).

SEM analysis included only those associations previously reported in the literature, or plausible associations when no previous studies were found. Based on recent systematic reviews on sedentary behavior and unhealthy food consumption,, 10 we considered that excessive screen time (TV, for example) could lead to unhealthy food consumption (sugarsweetened beverages, high-fat high-sugar foods, ultra-processed foods), and not the contrary. Figure shows our SEM model.

\section{Sensitivity analysis}

A sensitivity analysis was performed comparing the model with DMFT $=0$ and DMFT $\geq 1$, not as a continuous scale.

\section{Ethical aspects}

The research was approved based on the ethical guidelines provided in CNS resolution 466/12, CAAE 85647518.4.0000.0021. All participants and their parents/guardians provided their written informed consent.

\section{Results}

A total of 615 children agreed to participate in the study. From the 115 eligible public schools, 69 agreed to participate in the study. Internal reliability of the sedentary behavior instrument was acceptable with Cronbach's alpha of 0.82 .

The mean DMFT index in the State was 1.02. The caries experience of the study population $(\mathrm{DMFT} \geq 1)$ was $39.1 \%$. Of students living in fluoridated areas, $62.7 \%$ were caries-free with lower mean of caries experience $(\mathrm{DMFT}=0.92)$ than non-fluoridated areas, of which $47.4 \%$ were caries-free with DMFT $=1.79$. Table 1 shows the percentage of caries-free and the mean number of DMFT index according to all variables.

Adolescents who had 2 hours or less of sedentary behavior had a lower mean value of DMFT than their counterparts. The same pattern was observed comparing those with SB and caries-free. Concerning unhealthy food consumption, $73.1 \%$ of adolescents who had fewer unhealthy choices (up to 2 times/week) were caries-free, and had a lower mean DMFT than those with more unhealthy choices. Fifty-six percent of adolescents with moderate unhealthy choices ( 2 to 4 times/week) were caries-free and had a mean value of DMFT=1.29. Fewer (52.1\%) adolescents with a high frequency of unhealthy choices (more than 4 times/week) were caries-free and they had a higher mean DMFT= 1.33 than their counterparts.

Table 2 shows the SEM analysis. Higher sedentary behavior (more than 2 hours/day) [SC $=0.2195 \% \mathrm{CI}$ : $0.07-0.39)$ ] and higher unhealthy food consumption

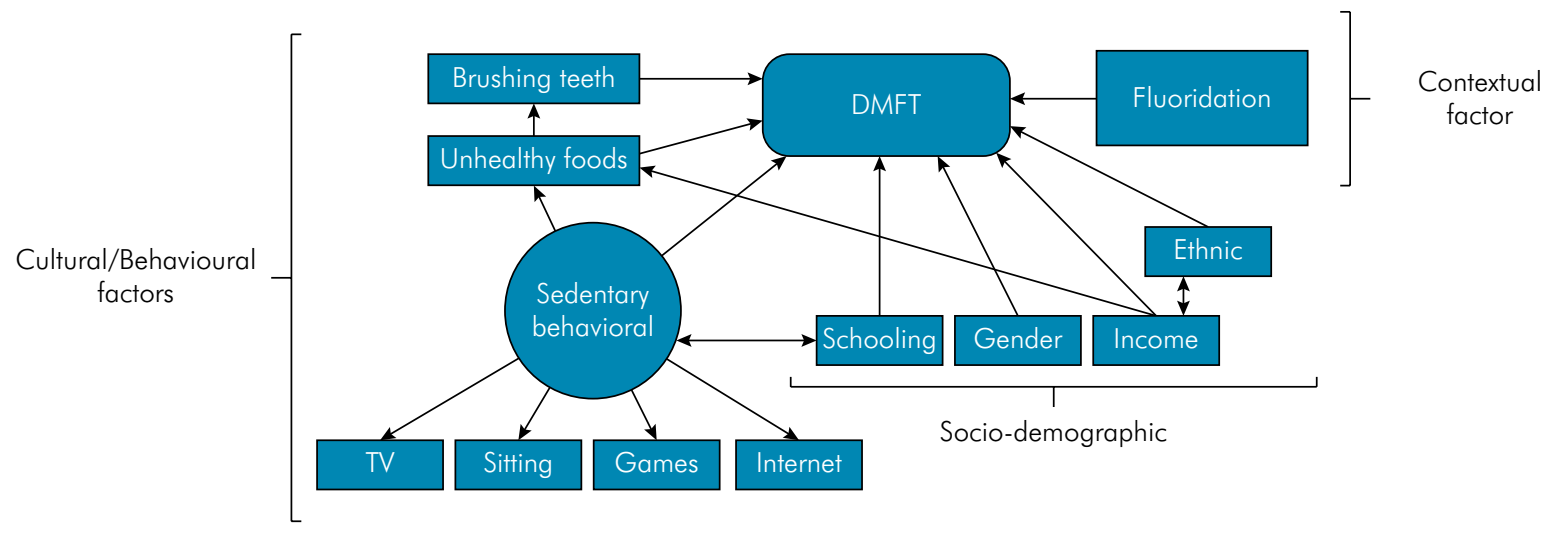

Figure. Theoretical framework according to Sisson's model of oral health inequalities. 
Sedentary behavior, unhealthy food consumption and dental caries in 12-year-old schoolchildren: a population-based study

Table 1. Descriptive characteristics and proportions of the Mato Grosso do Sul - Oral Health Survey (SBMS study 2018-19), for 12 year-old $(\mathrm{n}=615)$.

\begin{tabular}{|c|c|c|c|c|}
\hline \multirow{2}{*}{ Individual variables } & \multirow{2}{*}{$n=615$} & \multirow{2}{*}{$\%(95 \% \mathrm{Cl})$} & \multirow{2}{*}{$\begin{array}{c}\text { Caries free }(\mathrm{DMFT}=0) \\
\%(95 \% \mathrm{Cl})\end{array}$} & \multirow{2}{*}{$\begin{array}{c}\text { DMFT } \\
\text { mean }(95 \% \mathrm{Cl})\end{array}$} \\
\hline & & & & \\
\hline \multicolumn{5}{|l|}{ Ethnic group } \\
\hline Whites & 270 & $43.9(40.0-47.9)$ & $66.0(46.5-81.3)$ & $0.85(0.43-1.25)$ \\
\hline Brown & 266 & $43.3(39.4-47.2)$ & $55.6(40.9-69.4)$ & $1.29(0.39-2.20)$ \\
\hline Asian & 24 & $3.9(2.6-5.8)$ & 92.3 (22.9-99.7) & $0.50(0.43-1.01)$ \\
\hline Blacks & 32 & $5.3(3.7-7.3)$ & $37.3(25.7-50.7)$ & $1.81(1.54-2.10)$ \\
\hline Indigenous & 6 & $0.9(0.4-2.1)$ & $50.0(35.7-78.4)$ & $0.76(0.69-0.84)$ \\
\hline Missing & 17 & $2.8(1.7-4.4)$ & $52.9(40.3-65.4)$ & $1.59(1.34-1.87)$ \\
\hline \multicolumn{5}{|l|}{ Sex } \\
\hline Female & 315 & $51.2(47.3-55.2)$ & $63.0(49.5-74.8)$ & $0.96(0.27-1.65)$ \\
\hline Male & 300 & $48.8(44.8-52.7)$ & $60.1(36.8-79.5)$ & $1.10(0.52-1.67)$ \\
\hline \multicolumn{5}{|l|}{ Per capita Income (equalized) } \\
\hline Under poverty level (US\$120.4/month) & 216 & $35.1(31.4-39.0)$ & $56.3(24.1-83.9)$ & $1.18(0.20-2.16)$ \\
\hline Above poverty level & 376 & $61.1(57.2-64.9)$ & $64.0(50.7-75.5)$ & $0.97(0.45-1.50)$ \\
\hline Missing & 23 & $3.7(2.5-5.3)$ & $60.9(50.8-71.3)$ & $0.86(0.73-0.98)$ \\
\hline \multicolumn{5}{|l|}{ Parents' schooling } \\
\hline 1 to 4 years & 381 & $62.0(58.0-65.7)$ & $58.8(38.2-76.6)$ & $1.05(0.50-1.60)$ \\
\hline above 4 years & 234 & $38.0(34.3-42.0)$ & $70.4(34.5-91.4)$ & $0.96(0.40-1.57)$ \\
\hline \multicolumn{5}{|l|}{ Contextual } \\
\hline \multicolumn{5}{|l|}{ Fluoridation status } \\
\hline Yes & 411 & $66.8(63.0-70.4)$ & $62.7(53.4-71.2)$ & $0.92(0.62-1.23)$ \\
\hline No & 204 & $33.2(29.6-37.0)$ & $47.4(40.3-54.6)$ & $1.79(1.35-2.25)$ \\
\hline \multicolumn{5}{|l|}{ Unhealthy foods comsumption } \\
\hline Low (up to 2 times/week) & 168 & $27.3(23.9-31.0)$ & $73.1(66.9-78.5)$ & $0.59(0.31-0.87)$ \\
\hline Moderate (2-4 times/week) & 197 & $32.0(28.5-35.8)$ & $56.0(47.1-64.4)$ & $1.29(0.82-1.75)$ \\
\hline High (more than 4 times/week) & 217 & $35.3(31.6-39.2)$ & $52.1(35.1-68.6)$ & $1.33(0.61-2.05)$ \\
\hline Missing & 33 & $5.4(3.8-7.5)$ & $14.3(6.5-45.5)$ & $2.56(1.16-5.14)$ \\
\hline \multicolumn{5}{|l|}{ Sedentary behavior ( $\geq 2 \mathrm{hs}$ per day) } \\
\hline No & 338 & $55.0(50.9-58.9)$ & $71.9(54.0-84.7)$ & $0.77(0.45-1.46)$ \\
\hline Yes (sum of all domains $\geq 2$ hours day) & 251 & $40.8(35.9-46.5)$ & $47.5(36.3-58.9)$ & $1.42(1.06-1.77)$ \\
\hline Not reported & 26 & $4.2(2.9-6.1)$ & $45.5(40.7-50.3)$ & $1.03(0.87-1.88)$ \\
\hline \multicolumn{5}{|l|}{ Brushing } \\
\hline Twice or more per day & 318 & $52.7(47.7-55.6)$ & $73.6(40.5-90.1)$ & $0.76(0.24-1.60)$ \\
\hline Once per day or none & 234 & $38.1(34.3-42.0)$ & $53.1(46.2-59.8)$ & $1.40(1.02-1.77)$ \\
\hline Missing & 63 & $10.2(8.0-12.9)$ & $55.0(40.2-68.3)$ & $1.45(1.23-1.55)$ \\
\hline \multicolumn{5}{|l|}{ Cities } \\
\hline Campo Grande & 204 & $33.2(29.6-37.0)$ & $68.6(60.2-75.4)$ & $0.79(0.38-1.19)$ \\
\hline Dourados & 76 & $12.4(10.0-15.2)$ & $48.7(41.6-56.4)$ & $1.16(0.70-1.61)$ \\
\hline Corumbá & 131 & $21.3(18.2-24.7)$ & $32.1(28.4-37.1)$ & $1.80(1.58-2.03)$ \\
\hline Ponta-Porã & 68 & $11.1(8.8-13.8)$ & $48.5(40.9-55.7)$ & $1.62(0.95-2.29)$ \\
\hline Três Lagoas & 136 & $22.0(19.0-25.6)$ & $47.1(41.5-53.6)$ & 1.85 (1.31-2.39) \\
\hline
\end{tabular}

(more than 4 times/week) [SC $=0.23(0.10-0.45)]$ were associated with higher DMFT index than their counterparts. Moreover, higher parent's education, i.e., more than four years of study, were associated with lower DMFT index [SC= -0.59 (-0.93--0.25)]. In addition, cities with fluoridated water were associated with 
lower DMFT index [SC = -0.85 (-1.20--0.50)]. Higher consumption of unhealthy foods had a direct association with fewer tooth brushing times [SC $=-0.17(-0.22--0.12)]$, and families who had a per capita income above the poverty line had lower consumption of unhealthy foods [(SC $=-0.24(-0.38--0.11)]$, i.e., the higher the income, the fewer the unhealthy choices. Unhealthy food consumption mediated the effect of sedentary behavior on DMFT index [SC $=0.07(0.02-0.13)]$. Sensitivity analysis confirmed these findings.

Table 2. Structural equation models for sedentary behavioral, unhealthy food comsumption, and oral health, SBMS 18 ( $\mathrm{n}=615)$.

\begin{tabular}{|c|c|c|c|c|c|c|}
\hline \multirow{2}{*}{ Direct effects } & \multicolumn{3}{|c|}{ DMFT } & \multicolumn{3}{|c|}{ DMFT* $^{*}$} \\
\hline & SC & $95 \% \mathrm{Cl}$ & $\mathrm{p}$-value & SC & $95 \% \mathrm{Cl}$ & $\mathrm{p}$-value \\
\hline \multicolumn{7}{|l|}{ Behavioral } \\
\hline $\mathrm{SB} \rightarrow \mathrm{DMFT}$ & 0.21 & $(0.07-0.39)$ & 0.023 & 0.08 & $(0.03-0.12)$ & 0.001 \\
\hline Unhealthy food $\rightarrow$ DMFT & 0.23 & $(0.10-0.45)$ & 0.04 & 0.08 & $(0.03-0.14)$ & 0.002 \\
\hline $\mathrm{SB} \rightarrow$ Unhealthy food & 0.24 & $(0.16-0.32)$ & $<0.001$ & 0.24 & $(0.16-0.32)$ & $<0.001$ \\
\hline Brushing $\rightarrow$ DMFT & -0.40 & $(-0.72--0.09)$ & 0.012 & -0.12 & $(-0.20--0.03)$ & 0.004 \\
\hline Unhealthy food $\rightarrow$ brushing & -0.17 & $(-0.22--0.12)$ & $<0.001$ & -0.17 & $(-0.21--0.11)$ & $<0.001$ \\
\hline \multicolumn{7}{|l|}{ Socio-demografic } \\
\hline Sex $\rightarrow$ DMFT & -0.07 & $(-0.36-0.21)$ & 0.62 & -0.02 & $(-0.09-0.05)$ & 0.54 \\
\hline Parents' Schooling $\rightarrow$ DMFT & -0.59 & $(-0.93--0.25)$ & $<0.001$ & -0.19 & $(-0.28--0.11)$ & $<0.001$ \\
\hline Income $\rightarrow$ DMFT & -0.07 & $(-0.39-0.23)$ & 0.64 & -0.02 & $(-0.10-0.06)$ & 0.63 \\
\hline Ethnic $\rightarrow$ DMFT & 0.13 & $(-0.19-0.47)$ & 0.42 & 0.04 & $(-0.04-0.12)$ & 0.32 \\
\hline Income $\rightarrow$ Unhealthy food & -0.24 & $(-0.38--0.11)$ & 0.001 & -0.24 & $(-0.38--0.11)$ & 0.001 \\
\hline \multicolumn{7}{|l|}{ Contextual } \\
\hline Fluoridation $\rightarrow$ DMFT & -0.85 & $(-1.20--0.50)$ & $<0.001$ & -0.20 & $(-0.29--0.11)$ & $<0.001$ \\
\hline \multicolumn{7}{|l|}{ Indirect effects } \\
\hline \multicolumn{7}{|l|}{ Via unhealthy food } \\
\hline $\mathrm{SB} \rightarrow \mathrm{DMFT}$ & 0.07 & $(0.02-0.13)$ & 0.01 & 0.02 & (0.01-0.03 & 0.01 \\
\hline $\mathrm{SB} \rightarrow$ Brushing & -0.04 & $(-0.05--0.02)$ & $<0.001$ & -0.04 & $(-0.05--0.02)$ & $<0.001$ \\
\hline Income $\rightarrow$ DMFT & -0.08 & $(-0.14--0.01)$ & 0.03 & -0.03 & $(-0.04--0.01)$ & 0.01 \\
\hline \multicolumn{7}{|l|}{ Via brushing } \\
\hline Unhealthy food $\rightarrow$ DMFT & 0.07 & $(0.01-0.12)$ & 0.01 & 0.02 & $(0.01-0.03)$ & 0.01 \\
\hline \multicolumn{7}{|l|}{ Total effects } \\
\hline \multicolumn{7}{|l|}{ Behavioral } \\
\hline $\mathrm{SB} \rightarrow \mathrm{DMFT}$ & 0.29 & $(0.10-0.46)$ & 0.002 & 0.10 & $(0.05-0.14)$ & $<0.001$ \\
\hline Unhealthy food $\rightarrow$ DMFT & 0.30 & $(0.09-0.52)$ & 0.006 & 0.10 & $(0.05-0.16)$ & $<0.001$ \\
\hline \multicolumn{7}{|l|}{ Covariances } \\
\hline Income $\leftrightarrow$ Ethnic & -0.04 & $(-0.05--0.02)$ & 0.001 & -0.04 & $(-0.05--0.02)$ & 0.001 \\
\hline Parents Schooling $\leftrightarrow$ SB & 0.05 & $(0.02-0.10)$ & 0.005 & 0.05 & $(0.02-0.10)$ & 0.005 \\
\hline \multicolumn{7}{|l|}{ Goodness of fit } \\
\hline $\mathrm{AIC}$ & & 19140 & & & 17442 & \\
\hline $\mathrm{BIC}$ & & 19361 & & & 17663 & \\
\hline RMSE & & 0.06 & & & 0.06 & \\
\hline CLI & & 0.85 & & & 0.85 & \\
\hline TLI & & 0.80 & & & 0.80 & \\
\hline Chi2 & & $<0.05$ & & & $<0.05$ & \\
\hline
\end{tabular}

*DMFT used in sensitivity analysis (DMFT $=0$ and DMFT $\geq 1)$. 


\section{Discussion}

This study had two important findings. First, we found an association between the total sedentary behavior (on both weekdays and weekends) and dental caries experience measured by DMFT index. Second, we found that unhealthy food consumption mediated the effect of sedentary behavior on dental caries experience.

In a systematic review of the literature ${ }^{26}$ the authors found that sedentary behavior had harmful effects on health outcomes. The review indicated that public policies are needed, not only in the school setting but especially in the post-school period to reduce sedentary behavior among children and adolescents. Our study found an association of sedentary behavior of adolescents with caries experience. Moreover, consumption of unhealthy foods mediated the association between $\mathrm{SB}$ and DMFT index. A study conducted in China in $2014^{8}$ showed that approximately $50 \%$ of Chinese children and adolescents had dental caries and that television time was associated with a higher risk of caries. Our study also showed this association and corroborated these findings, but not only for television time. We measured the other three dimensions of SB, including games, internet, and sitting time, and adjusted our models for sociodemographic characteristics and fluoridation status,,$^{27,28,29}$ important predictors for oral health.

Using the theoretical framework by Sisson, ${ }^{14}$ it was possible to explain our findings through material explanation, related to the SES. In Brazil, between 2003 and 2010, there were unequal improvements in oral health in adolescents, especially related to dental caries ${ }^{11}$. Differences in the SES may influence access to food resources. SES is one of the main determinants of health inequalities. ${ }^{14}$ We found an inverse relationship between family income level and unhealthy food consumption, i.e., the lower the income, the higher the consumption of unhealthy foods. Secondly, concerning cultural and behavioral explanations, the growing increase in the use of social media $^{2}$ and easy access to electronic devices could lead adolescents to stay connected and inattentive with health care, which could decrease the frequency of tooth brushing (once per day or less). Sedentary behavior via unhealthy food consumption mediated the effect on tooth brushing, i.e., the higher the SB, the lower the tooth brushing frequency.

Moreover, through systematic reviews of the literature, sedentary behavior has been associated with unhealthy diets, such as ingestion of fewer fruits and vegetables and greater consumption of snacks and sugary and fatty foods ${ }^{9,10}$. We also found an association between higher consumption of unhealthy foods and lower tooth brushing (once or less per day). Besides, we found a direct association of SES with unhealthy food choices, corroborating the Sisson's model that people from lower SES are more likely to engage in behaviors that are bad for their health. Concerning contextual factors, water fluoridation is, more than a political issue, an ethical issue ${ }^{14}$ and it should be encouraged since only 19 of the 79 cities in Mato Grosso do Sul have water fluoridation. ${ }^{30}$

Future research should be carried out in cohort studies and life course perspective to verify whether SB mediated by unhealthy food consumption could affect the DMFT index. A systematic review and metaanalyses showed that interventions for sedentary behavior could decrease the time of sedentary lifestyle. ${ }^{31}$ These actions could benefit adolescents' oral health, given the higher risk of new carious lesions in those who already have caries. ${ }^{32}$

Because this was a cross-sectional study, some limitations must be pointed out. It is not possible to establish a causal relationship between the associations found in this investigation. On the other hand, because we used instruments validated in Brazil and abroad, especially for the evaluation of sedentary behavior, these associations may reflect in public policies to reduce sedentary behavior. Indeed, we only collected data from public schools, which limits the study generalization for all 12-yearold adolescents. Concerning representativeness of the study population, the five cities are the most representative of the four territorial macro-regions in the State and are the major affluent areas. Mato Grosso do Sul is an important Brazilian state of the Midwest region and responsible for a strong agribusiness that supplies the other geographical regions in the country. In Brazil, agribusiness 
accounts for approximately $25 \%$ of the GDP (Gross Domestic Product). The study also evaluated four dimensions of sedentary behavior and not only $\mathrm{TV} /$ screen time as others studies ${ }^{8}$ and used an instrument validated among European adolescents, the HELENA ${ }^{7}$ study, with good internal reliability. To the best of the authors' knowledge, this is the first study to verify the association of sedentary behavior on dental caries. Moreover, we used a valid instrument, the SISVAN ${ }^{21}$ questionnaire, developed by the Brazilian Ministry of Health to access unhealthy food consumption.

\section{Conclusion}

Ssedentary behavior, mediated by unhealthy food consumption, showed a significant association with dental caries experience. Public policies must address transdisciplinary actions to reduce sedentary behavior and unhealthy food consumption and promote water fluoridation. These actions can only be possible through intersectoral collaboration and partnership between the health sector and educational, nutritional, and physical activity sectors.

\section{Acknowledgements}

This study was financed in part by the Fundação Universidade Federal de Mato Grosso do Sul UFMS/MEC - Brazil and Statal Oral Health Coordination of Mato Grosso do Sul. The authors thank all research assistants, dentists and assistants who were involved in this study. We thank State Health Secretary of Mato Grosso do Sul, Statal Oral Health Coordination and all municipal oral health managers. We especially thank all the parents and children who took part in this study. The funders had no role in study design, data collection and analysis, decision to publish, or preparation of the manuscript.

\section{References}

1. Carson V, Hunter S, Kuzik N, Gray CE, Poitras VJ, Chaput JP, et al. Systematic review of sedentary behaviour and health indicators in school-aged children and youth: an update. Appl Physiol Nutr Metab. 2016 Jun;41(6 Suppl 3):S240-65. https://doi.org/10.1139/apnm-2015-0630

2. Barr-Anderson DJ, Sisson SB. Media use and sedentary behavior in adolescents: what do we know, what has been done, and where do we go? Adolesc Med State Art Rev. 2012 Dec;23(3):511-28.

3. Barnes J, Behrens TK, Benden ME, Biddle S, Bond D, Brassard P, et al. Letter to the Editor: Standardized use of the terms "sedentary" and "sedentary behaviours". Appl Physiol Nutr Metab. 2012 Jun;37(3):540-2. https:// https://doi.org/10.1139/h2012-024

4. Viir R, Veraksits A. Discussion of "Letter to the Editor: Standardized use of the terms sedentary and sedentary behaviours": Sitting and reclining are different states. Appl Physiol Nutr Metab. 2012;37(6):1256. https://doi.org/10.1139/h2012-123

5. Alberga AS, Sigal RJ, Goldfield G, Prud'homme D, Kenny GP. Overweight and obese teenagers: why is adolescence a critical period? Pediatr Obes. 2012 Aug;7(4):261-73. https://doi.org/10.1111/i.2047-6310.2011.00046.x

6. Katzmarzyk PT, Lee IM. Sedentary behaviour and life expectancy in the USA: a cause-deleted life table analysis. BMJ Open. 2012 Jul;2(4):e000828. https://doi.org/10.1136/bmjopen-2012-000828

7. Ferreira RW, Rombaldi AJ, Ricardo LI, Hallal PC, Azevedo MR. [Prevalence of sedentary behavior and its correlates among primary and secondary school students]. Rev Paul Pediatr. 2016 Jan-Mar;34(1):56-63. Portuguese. https://doi.org/10.1016/j.rpped.2015.06.005

8. Zeng X, Sheiham A, Sabbah W. The association between dental caries and television viewing among Chinese adolescents in Guangxi, China. BMC Oral Health. 2014 Nov;14(1):138. https://doi.org/10.1186/1472-6831-14-138

9. Shqair AQ, Pauli LA, Costa VP, Cenci M, Goettems ML. Screen time, dietary patterns and intake of potentially cariogenic food in children: a systematic review. J Dent. 2019 Jul;86:17-26. https://doi.org/10.1016/i.jdent.2019.06.004

10. Avery A, Anderson C, McCullough F. Associations between children's diet quality and watching television during meal or snack consumption: a systematic review. Matern Child Nutr. 2017 Oct;13(4):e124128. https://doi.org/10.1111/mcn.12428

11. Roncalli AG, Sheiham A, Tsakos G, Watt RG. Socially unequal improvements in dental caries levels in Brazilian adolescents between 2003 and 2010. Community Dent Oral Epidemiol. 2015 Aug;43(4):317-24. https://doi.org/10.1111/cdoe.12156

12. Roncalli AG, Sheiham A, Tsakos G, Araújo-Souza GC, Watt RG. Social factors associated with the decline in caries in Brazilian children between 1996 and 2010. Caries Res. 2016;50(6):551-9. https://doi.org/10.1159/000442899 
13. Narvai PC, Frazão P, Roncalli AG, Antunes JL. [Dental caries in Brazil: decline, polarization, inequality and social exclusion]. Rev Panam Salud Publica. 2006 Jun;19(6):385-93. Portuguese. https://doi.org/10.1590/S1020-49892006000600004

14. Sisson KL. Theoretical explanations for social inequalities in oral health. Community Dent Oral Epidemiol. 2007 Apr;35(2):81-8. https://doi.org/10.1111/i.1600-0528.2007.00354.x

15. Instituto Brasileiro de Geografia e Estatística - IBGE. Título da página consultada. Brasília, DF: Instituto Brasileiro de Geografia e Estatística; 2018 [cited 2019 Nov 27]. Available from: http://www.ibge.gov.br/home/default.php

16. Roncalli AG, Silva NN, Nascimento AC, Freitas CH, Casotti E, Peres KG, et al. [Relevant methodological issues from the SBBrasil 2010 Project for national health surveys]. Cad Saude Publica. 2012;28 Suppl:s40-57. Portuguese. https://doi.org/10.1590/S0102-311X2012001300006

17. Silva NN. Amostragem probabilística. São Paulo Edusp; 1998.

18. World Health Organization - WHO. Oral health surveys: basic methods. 5th ed. Geneva: World Health Organization; 2013 [cited 2019 aug 17]. Available from: https://apps.who.int/iris/bitstream/handle/10665/97035/9789241548649_eng.pdf?sequence=1

19. Rey-López JP, Ruiz JR, Ortega FB, Verloigne M, Vicente-Rodriguez G, Gracia-Marco L, et al. Reliability and validity of a screen time-based sedentary behaviour questionnaire for adolescents: the HELENA study. Eur J Public Health. 2012 Jun;22(3):373-7. https://doi.org/10.1093/eurpub/ckr040

20. Bland JM, Altman DG. Cronbach's alpha. BMJ. 1997 Feb;314(7080):572. https://doi.org/10.1136/bmj.314.7080.572

21. Ministério da Saúde (BR). Orientações para avaliação de marcadores de consumo alimentar na atenção básica. Brasília, DF: Ministério da Saúde; 2015 [cited 2019 Nov 27]. Available from: http://bvsms.saude.gov.br/bvs/publicacoes/marcadores_consumo_alimentar_atencao_basica.pdf

22. Celeste RK, Bastos JL. Mid-point for open-ended income category and the effect of equivalence scales on the income-health relationship. Rev Saude Publica. 2013 Dec;47 Suppl 3:168-71. https://doi.org/10.1590/S0034-8910.2013047004388

23. Pinheiro H, Freire MC, Bomfim RA, Ely HC, Frazão P. Cobertura e vigilância da fluoretação da água das águas nos municípios com mais de 50 mil habitantes da região Centro-Oeste. In: Frazão P, Narvai PC, organizadores. Cobertura e vigilância da fluoretação da água no Brasil: municípios com mais de 50 mil habitantes.. São Paulo: Faculdade de Saúde Pública da Universidade de São Paulo; 2017 [cited 2019 Jul 9]. 'p. 174-84. Available from: https://www.researchgate.net/publication/323073988_Cobertura_e_vigilancia_ da_fluoretacao_das_aguas_nos_municipios_com_mais_de_50_mil_habitantes_da_regiao_Centro-Oeste

24. Kline P. An easy guide to factor-analysis. Londres: Routledge; 2014.

25. Keith N, Hodapp V, Schermelleh-Engel K, Moosbrugger H. Cross-sectional and longitudinal confirmatory factor models for the German test anxiety inventory: a construct validation. Anxiety Stress Coping. 2003;16(3):251-70. https://doi.org/10.1080/1061580031000095416

26. Arundell L, Fletcher E, Salmon J, Veitch J, Hinkley T. A systematic review of the prevalence of sedentary behavior during the after-school period among children aged 5-18 years. Int J Behav Nutr Phys Act. 2016 Aug;13(1):93. https://doi.org/10.1186/s12966-016-0419-1

27. Spencer AJ, Do LG, Ha DH. Contemporary evidence on the effectiveness of water fluoridation in the prevention of childhood caries. Community Dent Oral Epidemiol. 2018 Aug;46(4):407-15. https://doi.org/10.1111/cdoe.12384

28. Iheozor-Ejiofor Z, Worthington HV, Walsh T, O'Malley L, Clarkson JE, Macey R, et al. Water fluoridation for the prevention of dental caries. Cochrane Database Syst Rev. 2015 Jun;(6):CD010856. https://doi.org/10.1002/14651858.CD010856.pub2

29. Schluter PJ, Lee M. Water fluoridation and ethnic inequities in dental caries profiles of New Zealand children aged 5 and $12-13$ years: analysis of national cross-sectional registry databases for the decade 2004-2013. BMC Oral Health. 2016 Feb;16(1):21. https://doi.org/10.1186/s12903-016-0180-5

30. Frazão $P$, Narvai PC, organizadores. Cobertura e vigilância da fluoretação da água no Brasil: municípios com mais de 50 mil habitantes. São Paulo: Faculdade de Saúde Pública da Universidade de São Paulo; 2017 [cited 2019 Jul 9]. http://www.livrosabertos.sibi.usp.br/portaldelivrosUSP/catalog/view/181/165/787-1

31. Prince SA, Saunders TJ, Gresty K, Reid RD. A comparison of the effectiveness of physical activity and sedentary behaviour interventions in reducing sedentary time in adults: a systematic review and meta-analysis of controlled trials. Obes Rev. 2014 Nov;15(11):905-19. https://doi.org/10.1111/obr.12215

32. Guedes RS, Piovesan C, Ardenghi TM, Emmanuelli B, Braga MM, Mendes FM. Presence of Initial Caries Lesions as a Risk Factor for Caries in Preschool Children: A Cohort Study. Caries Res. 2018;52(1-2):32-41. https://doi.org/10.1159/000479824 